\title{
Investigation of creep fatigue crack propagation in aluminium tube
}

\begin{abstract}
Tubular structure is extensively used from domestic to aviation kind of applications. Life and safety are most considered in designing tube structure that against failure. For the last 200 years of research output and understanding, it was estimated that about $90 \%$ of metal failures were due to the external or surface defect and environmental attacks. The present work had focused on damage tolerant fatigue life prediction on aluminium cylindrical structures. Endurance tests were conducted with a constant amplitude repetitive loading at both, in room and high temperatures. A notch is introduced by wire cut machined on external surface and in a straight line with circumferential orientation to represent an external defects and flaws. Crack growth rates were measured by imaging technique. The experimental results suggested that the creep fatigue life is shorter than conventional fatigue life. The effect of stress ratio is also presented. The fully reversed with high temperature results registered the most severe damage with tremendous of life reduction.
\end{abstract}

Keyword: Aluminium alloy; Creep crack growth; Creep fatigue; Pressure tube surface flaw 